
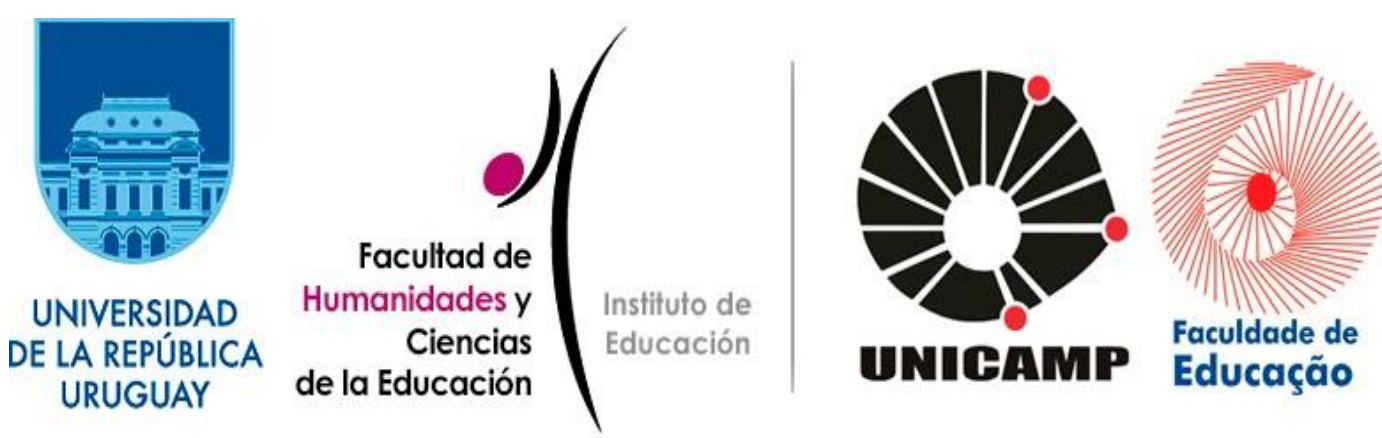

TRADUCCIONES | TRADUÇÕES

Fermentario V. 14, $\mathrm{N}^{\circ} 1(2020)$

ISSN 16886151

\author{
Instituto de Educación, Facultad de Humanidades y Ciencias de la Educación, \\ Universidad de la República. www.fhuce.edu.uy \\ Faculdade de Educação, UNICAMP. www.fe.unicamp.br
}

Una historia educativa de la caverna

(Sobre animales que van a «la escuela»)

Jan Masschelein

Traducción de Lourdes García

DOI: https://doi.org/10.47965/fermen.14.1.2

Recibido: 02/02/2020

Aceptado: 10/04/2020

... el ojo no siempre estuvo destinado para la contemplación...

M. Foucault

Hoy en día, tanto a nivel del discurso como de las políticas educativas, todo se trata de aprendizaje. Como una sociedad de aprendizaje intensivo, tenemos que encontrar formas de maximizar los logros de aprendizaje e investigar cómo poder hacerlo de forma eficiente y efectiva (cf. ej., Miller, Shapiro y Hilding-Hamann, 2008). Mientras tanto, hay muchas voces que abordan críticamente este foco en el aprendizaje. Cuestionan no solo la capitalización e instrumentalización que dicho foco supone sino también la relevancia de la noción misma de aprendizaje para la teoría y la práctica de la educación. De hecho, estas últimas vuelven a poner énfasis en la noción de educación, ya sea concentrándose en el aspecto de «enseñanza» o revalorando la idea de «estudio» (Biesta, 2013; Blacker, 2013; Lewis, 2013; Simons y Masschelein, 2008). Este artículo, si bien se muestra en la línea de estas voces más 
críticas, se basa en la convicción de que para lograr resistir a los discursos y políticas centradas en el aprendizaje y para recuperar la noción de educación es provechoso reconsiderar cómo entendemos la escuela, sin reducirla inmediatamente a una institución normalizadora o funcional. Por el contrario, la abordaremos como un cronotopo particular o espacio-tiempo de un animal educabile: poniendo a las personas y al mundo en compañía, de una forma particular, llevando a cabo una serie de operaciones específicas (suspensión, profanación, formación de la atención, ver más) permitiendo que la educación de hecho suceda. En otras palabras, reconsiderar la escuela implica intentar darle a la noción un sabor distinto. Comenzamos este intento en Defensa de la escuela. Una cuestión pública (Masschelein y Simons, 2013), y aquí el objetivo es continuar con este esfuerzo ofreciendo una historia educativa de la caverna que refiere a la escuela como evento y a la emergencia de la pedagogía, una historia que se diferencia de la famosa y aún poderosa historia filosófica de la caverna. Soy consciente de que no deberíamos perdernos en oposiciones binarias simplificando excesivamente, como ser entre una visión «filosófica» y una «educativa». No solo se puede entender cada una de ellas de maneras diferentes y variadas, sino que la relación que guardan entre sí es también intricada y compleja (Kohan, 2014; Larrosa, 2011). Mi objetivo aquí, sin embargo, no es comprometerme con un discurso o análisis argumentativo propiamente, sino más bien asumir en algún sentido lo que Tyson Lewis ha llamado el carácter fabuloso del pensamiento educativo, 1 su «precaria ubicación entre... verdad y ficción», la cual debe reconocer si es para «ser testigo de las dificultades de la educación como práctica sin respuestas seguras»y «reabrirnos a la experiencia de la educación» como una de potencialidad indeterminada (Lewis, 2012, pp. 340-341). Por lo tanto, espero que quien lee no confunda lo que sigue con una declaración de verdades filosóficas o la afirmación de una historia verdadera (ej.: de la escuela, del pedagogo) — aunque sí me refiera a algunos argumentos filosóficos o hechos históricosni por una simple historia ficticia. Es ficción, seguro, pero no falsedad. No es mentira, como manifiesta Rousseau (y Lewis nos lo recuerda). Es ficción también, en el sentido en que lo entiende Jacques Rancière: usando poderes lingüísticos comunes «para volver los objetos visibles y disponibles al pensamiento» (Rancière, 2000, p. 116). Con esta fábula o historia, combinando narrativa e imagen, entonces, espero contribuir a un pensamiento educativo de la escuela (y del pedagogo). Es un ejercicio de pensamiento educativo para resistir los discursos y políticas actuales en torno al aprendizaje, no criticándolos sino intentando poblar nuestra imaginación educativa con una historia,

$1 \quad$ No utilizo los términos filosofía de la educación o filosofía educacional deliberadamente. Ambos parecen implicar que filosofía es el asunto central. Aunque me gusta mucho la filosofía, quiero enfatizar la educación como el tema central. En alemán y holandés existe también la noción de Pädagogik o pedagogiek que se puede decir que son 'general' (Allgemein) o 'filosófica', siendo estos adjetivos que describen a Pädagogik o pedagogiek, que sería el sustantivo. Sugiero traducir estas nociones como 'pensamiento educativo/educacional' o ‘pensamiento pedagógico' (no teoría). 
una fábula diferente. Una que nos podría ayudar a acercarnos y a concebir la educación y la escuela, tanto teórica como prácticamente, de una manera algo distinta.

\section{La historia filosófica de la caverna}

La filosofía y la educación, incluyendo la filosofía de la educación, tienen al menos una clara conexión con las cavernas. De hecho, hasta el día de hoy, la famosa historia de la caverna de Platón es recordada y discutida una y otra vez en varios textos y cursos de filosofía y educación.2 La historia de Platón ofrece un tejido particular de iluminación, ilustración, educación y liberación, incluyendo la imagen de la 'conversión' como un (re)tornar hacia la luz(solar). Esta continúa apareciéndose no solo en nuestra imaginación filosófica sino también en la educativa.

No obstante las críticas a veces radicales que han sido hechas a las afirmaciones de Platón, la poderosa imagen de la educación como liberación de la caverna a descubrir, individualmente o con otros, la libertad a la que se puede acceder si viajamos hacia la luz continúa siendo atractiva para ambos, tanto filósofos y/como educadores (Burch, 2011). Esta imagen incluye la tarea de retornar a la caverna precisamente a liberar a aquellos cautivados por las sombras. Propongo llamar a la fábula3 de Platón la historia filosófica de la caverna, que afirma el rol de la filosofía, y, especialmente, la necesidad de la presencia del filósofo como maestro educador, sin el cual sería imposible salir de la caverna. El rol liberador del filósofo es uno que él/ella toma como una tarea heroica. Como Heidegger (1933/2001) dijo en su famoso comentario sobre la historia de Platón: el filósofo que retorna se expone a sí mismo o a sí misma a (el riesgo de) la muerte.

En la fábula de Platón, la caverna está valorada negativamente. Él no está pensando en sus habitantes históricos o prehistóricos. La caverna no es un refugio, sino una prisión. La palabra caverna es de hecho el resumen de una condición concreta de limitación e insuficiencia, la indicación de una vida fallida, no auténtica, sin alegría, insuficiente, insatisfactoria.4 Para Platón, esta condición es la normal o común; las personas en la caverna no son atopoi, sino que son todas personas (Blumenberg 1993, p. 37). Sin embargo, esta no es una condición natural o inalterable, sino un efecto de las influencias

2 En Salidas de la caverna, Hans Blumenberg (1993) recuerda varias otras conexiones con la cueva como metáfora o lugar real, desde Cicero hasta Montaigne, Bacon, Descartes, Jean Paul y Nietzsche.

3 Como afirma Pau Gilabert Barberà (2010, p. 105): «la conocida imagen de la cueva, cíḱ́v, revela una asombrosa e intrigante variedad de interpretaciones de esta imagen: "alegoría", "mito", "fábula", "parábola", "símil" y "comparación", por citar solo algunas». Puesto que hace hincapié especialmente en el elemento de creación de la imagen además de la narrativa, la noción de fábula parece adecuada. Usaré tanto fábula como historia sin entrar ahora en una discusión sobre su diferencia.

4 Para un análisis más rico y positivo del significado de la caverna en la Grecia Antigua, ver, por ejemplo Bachelard (1948) 
negativas (declive u opresión u olvido). La verdadera naturaleza de los humanos es precisamente el movimiento ascendente y de conversión, el movimiento de la paideia. Este movimiento los lleva a la contemplación, una capacidad5 que parece ser la capacidad natural y el verdadero destino del ser humano. Los humanos son criaturas cuyo destino es ser filósofos. De ahí que Hannah Arendt llamara a la alegoría de la caverna una «especie de biografía concentrada del filósofo» (2005, p. 29).

De la historia se desprende claramente que para ascender fuera de la caverna se requiere una fuerza externa que rompa las cadenas e inicie la conversión. Todo se refiere a lo de arriba y afuera, y el descenso del filósofo dentro de la caverna es en sí también forzado y tiene el objetivo heroico de liberar a los otros. Fundamentalmente, la historia ofrece una escena de impotencia, de una falta y de una necesaria trascendencia: cuellos y piernas humanos están encadenados en la oscuridad: «congelados, encadenados ante una pantalla, sin ninguna posibilidad de hacer nada ni de comunicarse entre sí» (Ibid., p. 31). Solo pueden ver aquello que está delante de ellos, incapaces de relacionarse entre ellos, atrapados en meras apariencias. Son seres que, como filósofos o de la mano del filósofo, tienen que dar (o ser dados) vuelta y ascender a la luz. La conversión es, entonces, un regreso al mundo, del cual los humanos habían caído en la oscuridad de una condición desastrosa. Esta historia filosófica de la caverna, contada en el contexto de una búsqueda del estado ideal y justo, es básicamente una historia sobre la conversión del alma como una iluminación que mantiene la soberanía trascendental del Ser y, en particular, que declara y afirma la filosofía y el filósofo como qué y quién se necesita para llevar al ser humano de la oscuridad a la luz (solar) (y de vuelta). Un comentarista escribió que la historia de Platón es una alegoría, la cual, según él, es una de las formas en que la filosofía se separa a sí misma de la mitología (Verhoeven, 1983). Implica, como mencionamos antes, que Platón no está escribiendo sobre otro mundo, sino que elabora una manera diferente de mirar a este mundo en el cual vivimos (Aun cuando su manera incluye hacer la distinción entre el mundo de la caverna y el mundo de las ideas).

\section{En la inspiradora lectura de Stanley Cavell de la historia de Platón, la caverna}

representa principalmente un lugar familiar desde el cual localizar el comienzo completo de lo que entendemos que la filosofía aspira a ser... Una percepción de que (la vida moral) se mueve desde un

55 Comparar: «De esto mismo, entonces», dije, «podría haber un arte, un arte del más rápido y efectivo cambio o conversión del alma, no un arte de producir visión en ella, sino en la suposición de que posee visión pero no la dirige correctamente y no mira donde debería, un arte de lograr esto». Platón, La República, Libro 7, 518d. Platón en 12 volúmenes, Vols. 5-6 traducido por Paul Shorey. Cambridge, MA, Harvard University Press; Londres, William Heinemann Ltd. 1969. http://www.perseus.tufts.edu/hopper/text?doc=Perseus\%3Atext\%3A1999.01.0168\%3Abook\%3D7\%3Apage\%3D518. 
sentido y estado de encarcelamiento a la liberación de uno mismo por el efecto transformador de lo que puede ser llamado filosofía (Cavell, 2005, p. 317).

Escribe sobre «guiar (el yo) a un camino de iluminación» (Cavell, 2005, p. 321). Aunque la filosofía «no habla primero» (Cavell, 2005, p. 324) sino que responde, esta respuesta es «el gesto de descender», marcando «la violencia del juicio maduro en la evaluación de la vida de otros. [...] Después de todo, les estamos diciendo que no saben lo que están diciendo" (Cavell, 2005, p. 326). Stanley Cavell se adhiere a la

idea de progreso filosófico no como de afirmaciones falsas a verdaderas, o de opiniones a conclusiones comprobadas (digamos tesis), o de la duda a la certeza, sino más bien de la oscuridad de la confusión al entendimiento iluminado, o digamos de la ilusión a la claridad, o de estar en un desconcierto intelectual a sentirse cómodo, seguro, confiado consigo mismo (Cavell, 2005, p. 328).

No pretendo entrar en una discusión con Cavell, cuya lectura de la historia es mucho más rica y variada de lo que puedo retratar aquí,6 pero permítanme señalar el hecho de que Cavell parece continuar, al menos en gran medida, el omnipresente relato filosófico que asimila la caverna con una imagen de encarcelamiento, desesperación, ignorancia, oscuridad, confusión, ilusión y confusión intelectual. El mismo Cavell se refiere también «al tormento, la dolencia, la extrañeza, el exilio, la decepción, el aburrimiento, el desasosiego» (2005, p. 329) como una condición de la cual no es necesario escapar, sino que tenemos que juzgar en relación con el «grado en el cual estas condiciones deben ser soportadas y tal vez dadas vuelta [...] constructivamente, productivamente, socialmente» (Cavell, 2005, p. 329). La filosofía entonces, se relaciona con un «sentido de decepción con el mundo» $\mathrm{y}$ «nuestro aprisionamiento en necesidades falsas» (Cavell, 2005, p. 382).

Permítanme, en contraste con esta visión filosófica, proponer ahora una visión pedagógica o educativa, que pueda abrir una historia de la caverna o fábula alternativa, que nos invite a reconsiderar la forma en que concebimos la educación y la filosofía, que cuestione el entramado de la iluminación,

\footnotetext{
$6 \quad$ No puedo ni pretendo tratar aquí todas las interpretaciones y lecturas de la historia de Platón (como la reciente y maravillosa de Bruno Latour que la interpreta como la puesta en escena de una tragicomedia; ver Latour 2016). Permítanme referirme al estudio de A. J. Bartlett (2011), que ofrece una relectura muy sofisticada del corpus de Platón, basándose en Alain Badiou, incluyendo la fábula de la caverna, y hace la firme afirmación de que la obra de Platón es solo sobre la educación y más específicamente sobre la educación por la Verdad. Sin embargo, al igual que muchos filósofos, olvida o descuida la relación entre educación y escuela y construye su interpretación sobre la diferencia entre opinión y verdad (y entre el filósofo preocupado por la verdad y el sofista preocupado solo por los intereses y los beneficios). La historia de la caverna que propondré aquí sugiere más bien que la educación no se trata principalmente de verdad u opinión y que los sofistas no son relevantes para el pensamiento educativo debido a su preocupación por el interés, sino tal vez porque primero que nada reconocieron al ser humano como animal educabile, como un ser errante sin destino (y orientación). Ver Jaeger (1973/1933).
} 
la educación y la liberación que constituye la historia filosófica de Platón. Esta fábula educativa no justifica ni afirma la necesidad primaria de un libertador o filósofo; no concibe la educación como conversión, sino que supone algunas sugerencias sobre el surgimiento de la escuela y la aparición del pedagogo como quien la conduce. Esta fábula pedagógica de la caverna es la historia de los seres que entran ella y dejan huellas en sus paredes, ofreciendo una escena de la educación del ser humano como una escena de potencia e inmanencia. Esta fábula no se trata de la ‘iluminación’ en el sentido de hacer un movimiento (volver) de la opinión a la verdad o de la ilusión a la claridad, sino de la luz que permite el comienzo de algo mientras se explora, se revela y se expone el mundo imaginándolo, haciendo imágenes (como inscripciones). Es la historia de los seres que se encuentran en este mundo de sombras en compañía de los bocetos, huellas, inscripciones que han hecho ellos mismos con sus manos, que abren sus vidas, y también los hacen soñar. Esta liberación, sin embargo, no apunta a la trascendencia sino a la inmanencia, no es una conversión o retorno sino un errar, como ahora elaboraré más a fondo en lo que podría llamarse tal vez, también, en primer lugar, una historia acerca de la aparición de la escuela o la fábula del animal que va a la escuela.

\section{El presente (Main-tenant) de la Caverna: El regalo del Mundo}

Si fuéramos a rastrear los elementos de esta fábula educativa, tendríamos que señalar una variedad de observaciones (científicas), reflexiones, comentarios e interpretaciones relacionadas con los hallazgos y estudios de todo tipo de trazos (dibujos, pinturas) en las paredes de las cavernas de todo el mundo. De hecho, estos han recibido atención no solo de paleontólogos, arqueólogos, antropólogos y espeleólogos, sino también de novelistas, artistas y... filósofos. La historia, por lo tanto, conoce muchas versiones, 7 pero las versiones que me interesan aquí son las que no pasan por alto la fenomenología de la caverna, es decir, las experiencias espaciales y temporales relacionadas con entrar a una caverna y permanecer en ella, como milieu8 particular o cronotopo. Aquellos que prestan atención al gesto del acto de trazarse en sí mismo, así como a la diferencia entre la forma en el que un texto y una imagen nos hablan (porque ver no es lo mismo que leer y escuchar, y una imagen puede compartir sin ser un mensaje, sino simplemente por estar frente a nosotros). Estas son versiones que no reducen las cavernas inmediatamente a lugares simbólicos establecidos y no catalogan las

\footnotetext{
$7 \quad$ Ver, por ejemplo, las reflexiones de George Bataille que sostiene que es precisamente a través de esta pintura rupestre, que eran la mayoría de las veces, pero ciertamente no exclusivamente, pinturas de animales (y, así, no solo de ellos mismos), que los 'hombres' se emanciparon de su naturaleza animal (Bataille, 1988, p. 262). O los muy influyentes comentarios de André Leroi-Gourhan que relaciona las pinturas con la apropiación de las cuevas como santuarios religiosos y las entiende en primer lugar como símbolos espirituales (ej., Leroi-Gourhan, 1965). Este enfoque es muy dominante hoy en día y muy presente en la obra de uno de los más famosos expertos franceses en arte paleolítico en general y en pinturas rupestres más particularmente, Jean Clottes (véase, por ejemplo, 2008).

$8 \quad$ N. de la T.: Continuaremos utilizando la palabra milieu en francés.
} 
actividades llevadas a cabo dentro de ellas inmediatamente como prácticas y reglas culturales o religiosas. Las versiones que me interesan reconocen la entrada a la caverna y las huellas en sí mismas, principalmente como movimientos y gestos. Además, me interesan no solo las hermosas pinturas de animales que ofician como el comienzo del arte, sino también, y principalmente, las imágenes de las manos (que se encuentran en muchas cavernas de todo el mundo y que datan de variados períodos de tiempo) 9 y en las rayas, estrías, puntos y manchas, en los bocetos, rasguños, trazados y dibujos que a menudo no son figurativos y se superponen. En lo que sigue, me referiré brevemente a los escritos de John Berger y Jean-Paul Jouary, pero me apoyaré en particular en el trabajo de Marie-José Mondzain, que elabora las anteriores, breves pero muy interesantes, meditaciones de Jean-Luc Nancy sobre las imágenes de manos en las paredes de las cavernas. Mientras que Nancy se refiere casi exclusivamente a los trazos de manos encontrados en la Cueva de Cosquer descubierta cerca de Marsella en 1991, Mondzain basa su ficción principalmente sobre los hallazgos relacionados con el descubrimiento de la Cueva de Chauvet en la región francesa de Ardèche en 1994. Esta cueva contiene algunas de las pinturas murales más antiguas descubiertas hasta ahora (que datan de aproximadamente 32.000 a. C.), pinturas que están muy bien conservadas y de una belleza extraordinaria10. Como ella misma lo afirma, Mondzain construye una «fantasía» (2007, p. 26), que no cuenta la historia de un retorno de los humanos a la luz de la verdad eterna que brilla desde atrás. El ser humano de la Cueva de Chauvet entra en la caverna en lugar de huir de ella y produce luz con y en sus propias manos. Estas manos iluminadas, según Marie-José Mondzain, revelarán su poder o capacidad de hacer una imagen, incluyendo precisamente una imagen de las manos, una imagen de un ser que se convierte a la vez en el espectador de la obra de sus manos, no simplemente como un objeto o herramienta, sino como una imagen, inaugurando así la mirada humana sobre el ser humano y sobre el mundo. Como dijo Max Horkheimer:

Los hechos que nuestros sentidos nos presentan están representados socialmente de dos maneras: a través del carácter histórico del objeto percibido y a través del carácter histórico del órgano que percibe. Ambos no son simplemente naturales; están conformados por la actividad humana, y sin

9 El proyecto español Handpas, iniciado recientemente, se centra precisamente en documentar y exhibir representaciones de manos del período paleolítico en Europa. Véase: http://handpas.eu/en/project/.

10 Una belleza que es representada de manera fascinante por Werner Herzog en un documental llamado La cueva de los sueños olvidados. El título resuena de manera interesante con otra de sus películas, Kaspar Hauser, de quien se dice que ha estado encerrado en una cueva (no muy diferente a los prisioneros de la caverna de Platón) y que no ha tenido sueños hasta algún tiempo después de su liberación. Sugiere que para tener sueños, y eso significa también para tener la posibilidad de relacionarse con lo que sucede y no solo ser absorbido o encerrado en ello, necesitamos algún tipo de (re)presentación. Igualmente interesante es que, en esta película, justo antes de que Kaspar sea sacado de la cueva, aprende a dibujar/escribir en un pedazo de papel en blanco. 
embargo el individuo se percibe a sí mismo como receptivo y pasivo en el acto de la percepción (1937/2002, p. 200, la cursiva es mía).

Esto se repite en la observación de Foucault de que «el ojo no siempre estuvo destinado a la contemplación» (Foucault, 1984, p. 83). Nancy y Mondzain, entonces, sugieren que los ojos humanos no estaban desde el principio destinados a la consideración, el pensamiento y la apreciación. Es a estas imágenes, hechas por la mano en la caverna, de esto va esta historia, que debemos el hecho de tener ojos que se abren al mundo de una manera incomparable; es a estas imágenes que debemos la experiencia de ser capaces de contemplarnos 11 a nosotros mismos y al mundo, convirtiéndonos en seres que pueden comenzar (de nuevo). O para decirlo de otra manera: nuestra capacidad de mirar (mirar, pero también respetar, considerar) emerge de nuestras manos descubriendo la capacidad de hacer imágenes. Viéndolo así, podemos continuar aclarando el registro específico de la representación, el gesto específico de «monstracion»12 (que es el término utilizado en la traducción inglesa de la obra de Nancy para el francés monstration, que se refiere al acto de exponer, exhibir a los ojos de un público), y la experiencia específica que pasaríamos por alto si relacionáramos las imágenes directamente a las prácticas religiosas o rituales que deben ser entendidas.

Considerando la pintura de las manos en las paredes de las cavernas, Mondzain (2007, pp. 21-58) distingue tres actos, u operaciones, ninguna de las cuales es sobre el retorno o la conversión.13 El primer acto es el ser-deviniendo-humano al estirar su brazo, que tanto se apoya en la pared y se separa de ella en el mismo movimiento: la medida de un brazo que es, de hecho, el primer distanciamiento de uno mismo del plano en el que un vínculo se compondrá a través del contacto. Ya no es como en el exterior, en el sol, donde sus ojos pueden mirar mucho más lejos de lo que sus manos pueden tocar. Bajo el sol, sus ojos son herramientas de vigilancia, previsión o providencia; miden una distancia a ser cubierta o instalada (tomada). Afuera, sus ojos tienen un horizonte distante que escudriña. El

11 N. de la T.: En este caso el autor utiliza la palabra en inglés behold, pero la presenta con paréntesis (be)hold, lo cual haría referencia no solo a la contemplación en sí, sino también al hecho de ser o estar 'sostenido' (Mismo uso de (be)hold en la p. 13).

12 N. de la T.: En adelante se empleará la palabra monstración como traducción al castellano del gesto de 'monstration' (Nancy, 1996).

13 Arendt escribe que la parábola o la alegoría de la caverna «se desarrolla en tres etapas, cada una de ellas designó un punto de inflexión, un giro, y los tres juntos forman ese... giro de todo el ser humano, que para Platón es la formación misma del filósofo» (Arendt 2005, p. 29, la cursiva es mía). Estos tres giros son la liberación de las trabas que encadenan el futuro filósofo, lo que Arendt llama el giro del científico que «se da la vuelta para averiguar cómo las cosas son en sí mismos, independientemente de las opiniones de la multitud». Se aparta de «sus doxai, qué y cómo las cosas les parecen», desde su posición. El segundo giro es cuando este no se satisface con el fuego en la cueva y encuentra una salida de la cueva y un acceso a «las ideas, esencias eternas de cosas perecederas y de hombres mortales», de donde «debe regresar (la tercera etapa) a la cueva como su hogar terrenal», donde ya no puede sentirse en casa (Arendt 2005, pp. 29-30). Como indicaré, Mondzain también distingue tres actos, pero ninguno de ellos será concebido como un giro. 
horizonte es la experiencia de una brecha que despierta un sueño de dominio, provoca el deseo de conquista o inspira el asombro (paralizante). El horizonte es la experiencia de una brecha que despierta un sueño de dominio, provoca el deseo de conquista o inspira (paralizando) el asombro. La inaccesibilidad del horizonte se encuentra con las figuras imaginarias de la trascendencia. Pero en la caverna, el horizonte no está más allá de la modesta propuesta de la longitud de un brazo. Es la inmanencia de un cuerpo a cuerpo o de un cuerpo a la pared. El brazo extendido, la mano colocada en la pared para mantener una distancia. Mantener se refiere al maintenue francés, que regresa, como Mondzain y Nancy afirman, en el main-tenant, es decir, la palabra francesa para 'ahora' o 'presente'. Este mantenimiento es a la vez una reunión, un entre-tien ('sosteniendo entre') en el sentido de que el ser humano se sostiene a sí mismo — en francés: se tient — ante la pared, que forma el plano y constituye el horizonte (sin horizonte) de la mirada y tiene su propia posición (tenu(r)e o sostenimiento).

Y lo que llegará entre ellos está en las manos del ser humano. El ojo está sometido al orden de las manos. Este gesto de distanciamiento y vinculación constituye la primera operación.

El segundo acto se refiere a los pigmentos. En las paredes de la caverna, las manos crean una imagen de sí mismas, presentándolas a los ojos — no dándoles la forma o plegándolas a las herramientas, sino sumergiéndolas directamente en la pintura, posándolas en la pared y presionándolas durante algún tiempo, creando lo que se llaman manos positivas - . O, se supone, tomando la pintura en la boca y escupiéndola en la mano presionada contra la pared, creando las llamadas manos negativas. Así surge un nuevo gesto, que también marca literalmente una distancia — la longitud del brazo — que es sostener (en) la mano como un gesto de monstración, mostrando la mano a distancia. Este gesto implica que el propósito y el uso de la mano ha cambiado; no realiza actos de supervivencia (pesca, caza, agricultura) ni de hacer el amor, ni de fabricar objetos o herramientas. La mano ha dejado de ser una mano que agarra, corta, talla, o incluso acaricia, y la boca ha dejado de ser una boca que muerde, rasga o traga. Los usos de la boca y la mano ya no son el prensil, el posesivo, el de alimentación o el depredador, ni los de cuidado o amor, sino más bien los de establecer un doble movimiento de alcanzar, con las manos y la boca. El ser humano respira en su mano, que no sostiene nada, pero que mantiene ese ser en relación con la pared. Ella inhala, exhala, recibe la pintura y luego la pasa.14 El momento de la expulsión, una salida de líquido, es la puesta en escena que hace que un exterior en la

14 Permítanme hacer un comentario adicional para referirme a Tim Ingold indicando que es «con todo nuestro ser — indisolublemente cuerpo y alma — que respiramos». Se refiere al ensayo de Merleau Ponty Ojo y mente, afirmando que «realmente hay inspiración y expiración del Ser» como la «esencia de la percepción» (Ingold, 2015, pp. 67-68). 
pared sea (un) trabajo. Como dice Nancy, el francés maintenant significa 'sujetar por/en la mano'; pero la mano no es un lugar estable, lo que sugiere que será liberada, que el ahora está entre sujetar y liberar o soltar (Nancy, 2016):

La mano posada, presionada contra la pared, no agarra nada. Ya no es una mano prensil, sino que se ofrece como la forma de un agarre imposible o abandonado. Un agarre que bien podría dejar ir. El agarre de una liberación: la liberación de la forma (Nancy 1996, p. 72).

El tercer acto es la retirada. La mano tiene que replegarse. El cuerpo tiene que separarse de su soporte. Pero no es su mano, la que está cubierta de pigmentos, la que el ser humano está mirando. Más bien, ante sus ojos aparece una imagen, su imagen, que ahora puede ver porque su mano ya no está allí. Esta mano como imagen, según Mondzain, no tiene ninguno de los poderes que el fabricante de herramientas reconocería. Sin embargo, en la suspensión de sus poderes manuales, la imagen indica la capacidad o potencia de la mirada que la mira, que la aprecia. Es un trabajo, un hacer que indica una capacidad fundacional del sujeto para componer su primera mirada del vestigio de repliegue. Retirarse es producir la propia imagen y entregarla a la mirada de los ojos, como un vestigio vivo, pero separado de uno mismo. Como explica Mondzain, el ser humano ya había visto su mano, pero no su mano como una imagen de sí mismo que se mantiene fuera de sí mismo en la pared inanimada. Esta mano, nacida de la sombra, es ahora sombra ella misma. Lo que nos llega de esta interacción es el trabajo de una separación y un vínculo, que este signo compone con aquello de lo cual se separa. Verse a sí mismo es siempre verse a sí mismo en y desde la distancia. En la caverna, sin embargo, este ver no es verse a sí mismo reflejado en la superficie espejada del agua o en el ojo del otro.15 Verse a sí mismo es siempre verse a sí mismo en y desde la distancia. En la caverna, sin embargo, este ver no es verse a sí mismo reflejado en la superficie espejada del agua o en el ojo del otro. La pared es un espejo del ser humano, aunque no un espejo especular, y esta mano es el autorretrato no especular del ser humano. Y lo mismo ocurre con el mundo: es entregado a la mirada de los ojos, pero es separado de sí mismo, a la distancia. Ver el mundo es siempre verlo a y desde la distancia, pero aquí la vista no es la de la cima de una montaña, de los senderos en el bosque, o en la llanura. Es ver imágenes en un muro.16 Imágenes de animales, imágenes de las manos, producidas de forma autónoma por las manos ante los ojos, como pre-sentadas, como un prae-esse que mantiene una relación y, por ende, es también un posible inter-esse.

15 En la pupila del ojo como una pequeña muñeca, como Platón sugiere en las Alcibíades 1. 133a.

16 John Berger escribe: «El arte tradicional chino miraba a la tierra desde la cima de una montaña confuciana; el arte japonés miraba de cerca en torno a los biombos; el arte renacentista italiano observaba la naturaleza conquistada a través de la ventana o el marco de la puerta de un palacio» (John Berger, 2002). 
En esta maravillosa fantasía, como la cuentan Mondzain y Nancy, la caverna como un limitado espacio amurallado no aparece como una prisión, ofreciendo una escena de impotencia y trascendencia. En cambio, ofrece una escena de potencia e inmanencia, de liberación, en un sentido particular. Permítanme indicar algunas otras características de este sitio y escena.

En primer lugar, las cavernas en las que se hacen las pinturas - a menudo muy lejos de la entrada y en puntos difíciles de las paredes irregulares - no son hogares familiares. No hay rastros de ocupación. Pero tampoco deben ser vistos rápidamente como santuarios religiosos, que inmediatamente dan a las imágenes pintadas y al sitio mismo un lugar significativo dentro de un culto. No hay, en efecto, como escribe Nancy, ninguna razón para prestar a las imágenes cualquier otro sentido que no sea el sentido sin significación de la exposición...: no un sentido perdido, ni uno que esté distanciado o diferido, sino un sentido dado en la ausencia como en la más simple, extrañada simplicidad de la presencia ser $\sin$ ser o sin esencia que lo funde, lo cause, lo justifique o lo santifique-. Ser simplemente existiendo... todo su ejercicio es superarse a sí mismo, no siendo en sí mismo nada más que el absoluto desapego o distanciamiento de lo que no tiene fundamento en la propiedad de una presencia... La imagen, aquí, no es el conveniente o inconveniente doble de una cosa en el mundo: es la gloria de esa cosa, su epifanía, la distinción de su propia masa y su propia apariencia. La imagen elogia la cosa como separada del universo de cosas... (Nancy, 1996, pp. 72-73, la primera y última cursiva son mías)

La caverna es un lugar de separación, partida, distanciamiento y suspensión. La partida de un mundo de vida diaria, la separación del ciclo eterno de vida y muerte, del ciclo del cambio de las estaciones, de las variaciones de temperatura y del ritmo del día y la noche. Un sitio de suspensión: imágenes de las manos, de humanos, animales, de objetos. Las manos ya no son herramientas, los animales ya no son presas o depredadores, retirados del ciclo de reproducción y supervivencia, desnudos y hermosos. La imagen no es el concepto caballo o bisonte o mano, sino una imagen que se hace y que contiene una profanación y es una suspensión (temporal) del caballo o bisonte en su entorno natural o social (liberado, presentado, expuesto), una suspensión del poder ordinario de las manos. John Berger escribe: «Salga de la caverna y vuelva a entrar en la fiebre del tiempo que pasa. Retome los nombres. Dentro de la caverna todo es presente y sin nombre» (2002). Las imágenes muestran algo y eso significa dejarlo a un lado «a una distancia de presentación, para salir de la pura presencia» (Nancy, 1996, p. 70), implicando y ofreciendo la posibilidad de considerar y explorar nuevas relaciones con uno mismo, con los demás y con el mundo, a distancia. No el tipo de distancia desde la cima de una montaña que evoca la reverencia por la grandeza del mundo o que provoca la imaginación de la 
conquista, sino la distancia de un brazo (a la mano, al alcance). La mano «abre una distancia, que suspende la continuidad y la cohesión del universo, para así abrir un mundo» (Nancy, 1996, p. 75). Es el lugar de otra experiencia espacial y temporal, un cronotopo o milieu espacio-tiempo particular (incluyendo la temperatura, el aire, el suelo, el humo, los olores, el silencio, los sonidos, la oscuridad, etc.). Es un lugar real pero también uno sin lugar en el orden habitual de los lugares, un lugar sin lugar. Existe en tiempo real pero fuera del tiempo regular, un tiempo fuera del tiempo. Nancy lo llama también «tiempo adicional» (1996, p. 74). De manera similar, lugar sin lugar y tiempo fuera del tiempo fueron frases utilizadas por Foucault para describir la heterotopía y la heterocronía (Foucault, 1986). Dentro del contenido espacio singular y el oscuro tiempo singular de la caverna, el ser humano se convierte en maestro de la luz, maestro del día y la noche, ya que tiene la antorcha de carbón que encendió con sus propias manos y está lanzando una luz titilante en las paredes. Como Mondzain sugiere, el ser que se convierte en humano no debe ser visto como caído de la luz del cielo y sometido a los poderes de otros o de Otro, más grande que él, definiéndose a sí mismo como impotente, incapaz o débil. Es más bien un ser que entra en la caverna para dar forma a su propia definición, creándose a sí mismo y al mismo tiempo, siendo creado mediante el trabajo de sus propias manos. La teología, añade, prefiere hacer que los seres humanos vengan de la mano de un alfarero divino. El humano de la caverna fabrica su horizonte y se da a luz a sí mismo al extender sus manos a una irreductible y vivificante extrañeza: sus propias manos (sí mismo). Este arte como una fabricación de imágenes que, como sugiero, es crucialmente, también, en primer lugar, un intento, ejercicio, bosquejo que no es dirigido por un fin predefinido o un logro proyectado sino siempre errado- hace que el mundo sea visible o perceptible (es decir, lo hace aparente) en una nueva forma. Nos hace perceptibles a nosotros de una nueva manera: «... la demostración de... sí mismo fuera de sí mismo, el exterior de pie para sí, y él siendo sorprendido en frente de sí mismo» (Nancy, 1996, p. 69).

Este ser transforma una relación de fuerza, donde lo real la aplastaba, en una relación literalmente imaginaria a través de lo que podríamos llamar una espacialización como gramatización: hacer imágenes, trazar bosquejos.17 Ya no hay tiempo solo para vivir y tiempo para trabajar y amar, ahora hay también tiempo para la atención y la contemplación: «la puesta en escena de una escenografía en la cual la atención se centra en un conjunto de inscripciones dramatizadas», para ocupar de las palabras de Bruno Latour (1986, p. 17).18

17 Véanse también las esclarecedoras observaciones de Vilém Flüsser (2011) sobre la retirada del mundo de los objetos a través del acto de la creación de imágenes.

18 Permítanme, en este contexto, recordar brevemente un primer texto de Latour (1986) sobre la visualización y la cognición, en el que señala un pensamiento con ojos y manos y donde nos invita a no relacionar la especificidad de la 
Aquí, la relación en la que el humano está ligado por el poder de una realidad específica se transforma en una relación que ofrece la posibilidad de relacionarse con el yo y con el mundo y comenzar a interactuar con ese mundo. Como dice Nancy:

... el ojo, que hasta entonces no había hecho nada más que percibir las cosas, se descubre a sí mismo viendo. Ve esto, que ve. Ve que ve allí; ve allí donde hay algo del mundo que se muestra a sí mismo (Nancy, 1996, p. 79).

Ofrece a este ser la capacidad de (re-)nacimiento, de tener la experiencia de contemplarse, de tener a (la distancia de) la mano, la experiencia de un main-tenant, de un ahora o pre-sent que le permite a este ser convertirse en la causa de sí mismo, de venir al mundo y entrar en relación con él. Este ser se contempla frente a una pared de roca, en la opacidad de un cara a cara con esta pared como horizonte ( $\sin$ horizonte), masiva, muda, y sin mirada. Frente a una pared en la que el propio ser arroja luz; no la luz del sol o la luz divina sino la luz de la antorcha sostenida en sus manos. La pared como una «interrupción y el aislamiento de una zona que no es ni un territorio de vida, ni una región del universo, sino un espacio en el que dejar venir... toda la presencia del mundo» (Nancy, 1996, p. 75). Presente también puede significar regalo. Este presente, o ahora, es un regalo, dado: «Se me da, Es gibt o Es ist mir gegeben... me es dado... la apertura del tiempo que no está dentro del tiempo» (Nancy, 2016, p. 2)

También es importante mencionar que este ser entra en la caverna voluntariamente y que tiene que encontrar el coraje para entrar en la caverna (que es aún más oscura que la noche más oscura, y por lo tanto es incómodo, impidiendo cualquier previsión). Este ser hace un esfuerzo vital, ya que las pinturas están a menudo muy lejos de la entrada y en lugares de difícil acceso. No se mueve por la distorsión o la confusión; entra en la caverna, a tientas, emocionado, por curiosidad y, como Berger escribió después de su excepcional visita a la Cueva de Chauvet en 2002, por «la necesidad de compañía». Por lo tanto, lo que busca en primer lugar, no es la verdad sino el encuentro. Berger comenta que dentro de la caverna hay un equilibrio entre el miedo y la sensación de protección. En la vida, dice, la mayoría de los animales representados en las paredes eran feroces, pero en la caverna la relación es la de «respeto, sí, un respeto fraternal» (Berger, 2002). Además, las imágenes de la pared inauguran no solo el ser humano como monstrador y espectador, sino también a una comunidad como un público de espectadores: una colección contingente de cualquier singularidad ocupa el espacio de la caverna, la cámara donde se hacen las imágenes en la pared. Una comunidad no constituida por una

ciencia moderna con la existencia de diferencias culturales o con la feliz existencia de mentes especiales, sino con explicaciones que tengan en cuenta las manos y las inscripciones que trazan sobre superficies planas creando un dispositivo óptico que (re)presenta el mundo ante los ojos. 
identidad o pertenencia compartida (a una familia, a una tribu, a un culto religioso), sino por una relación con algo en la pared, por una presencia en un lugar determinado. Una cámara potencialmente poblada por otros y otras cualesquiera que ocupen el espacio, cerca o al lado, como contacto. Las imágenes no tienen un destinatario o respuesta predefinidos o definitivos; son los vestigios de la presencia humana, y la colectividad de los espectadores no se basa en la identificación psicológica con el productor de las imágenes y sus deseos, sino que se basa en estar en contacto como y espectadores del mundo.

\section{El fin (sin fin): Sobre animales que van a la escuela}

Permítanme ahora dar un giro o torsión adicional a esta fábula de la caverna a partir de cuatro observaciones. Primero, en sus reflexiones sobre las pinturas rupestres, Nancy también escribe que la

... figura trazada es esta misma apertura, el espacio por el que el hombre es traído al
mundo, y por el que el mundo mismo es un mundo: el acontecimiento de toda
presencia en su absoluta extrañez. Así, la pintura que comienza en las grutas [...] es
en primer lugar la monstración del comienzo del ser, antes de ser el comienzo de la
pintura (Nancy, 1996, p. 70, la cursiva es mía).

En segundo lugar, en su libro Préhistoire de la beauté. Et l'art créa l'homme (La prehistoria de la belleza. Y el arte creó al hombre), que se centra principalmente en las pinturas rupestres, Jean-Paul Jouary sugiere que no eran ya dadas (innatas o adquiridas) las capacidades humanas (por ejemplo, de imaginación) que dieron lugar a que se realizaran las pinturas rupestres, sino que fueron las prácticas en evolución (y las correspondientes tecnologías) que permitieron que esas capacidades surgieran y se desarrollaran. Él además elabora la idea de que no es porque seamos humanos que experimentamos placer estético o anhelo de él, sino que es porque creamos (es decir, ¡ejercitamos!) que tales sentimientos y percepciones pudieron surgir y que nos convertimos y nos continuamos convirtiendo en «humanos». Añade que este arte, o estos ejercicios, «produjeron» la escritura, la numeración, las mitologías y varias formas de conocimiento (Jouary, 2001 y 2012). En tercer lugar, el gesto que más atrae la atención de Mondzain y Nancy es precisamente el de hacer la imagen de las manos presionándolas a la pared, el cual se ve como el primer gesto, y es arte solo en un sentido muy general. No es todavía (el arte de) la pintura, sino el gesto que los niños todavía hacen hoy en día. Cuarto, la ubicación, es decir, el cronotopo particular, es por supuesto crucial de varias maneras para esta historia del ser-deviniendo-humano. Si el «arte» creó al «hombre», como sugiere Jouary, entonces la 
evolución de este arte se hizo posible en este lugar contenido sin lugar, este tiempo oscuro sin tiempo, donde el mundo de la vida está desplazado.19

Desde aquí, creo que podemos llamar a esta historia, sin forzarla demasiado, la historia educativa de la caverna y podemos darle a este lugar el nombre de «escuela». Se ha sugerido a menudo que la caverna de Platón es también el paradigma del cine. Y los investigadores de las pinturas rupestres prehistóricas indican que algunas han sido hechas de una manera tan ingeniosa que a la luz parpadeante de las antorchas aparecen en realidad como imágenes en movimiento (Azéma, 2011). Pero si tenemos en cuenta las operaciones de separación, suspensión y profanación, el tiempo fuera del tiempo, el lugar sin lugar, la creación de un público atento y contemplativo, las condiciones físicas y las tecnologías involucradas, junto con los ejercicios de la mano y el ojo, que aún no están seguros y no saben todavía lo que hacen o ven (los bosquejos, los puntos, las estrías) para que lo humano se forme a sí mismo en un esfuerzo vital basado en la curiosidad (es decir, buscando compañía y no, en primer lugar, la verdad) y el coraje (que no es para el conflicto sino para el encuentro y la exploración), pareciera que también podemos sugerir que ella da entonces testimonio del acontecimiento de la escuela,20 como la forma en que un ser sin destino natural, sin fin, un ser errante, se forma a sí mismo y a su apreciación (en varios sentidos, incluyendo considerar, mirar, contemplar, preocuparse, respetar, prestar atención, relacionarse) del mundo a través de tecnologías, ejercicios y prácticas que inventa o utiliza, pero que también, a su vez, crean ese ser y sus artes, que lo abren y lo exponen a un mundo que le es dado o presentado.

El ser-deviniendo-humano/alumno es un animal que va a la escuela. Es decir, un animal que no solo se inicia y socializa, sino que también descubre en la escuela su potencia para formarse a sí mismo y al mundo, un ser sin destino natural o proyectado (es decir, no está definido). Un ser que experimenta el main-tenant, el presente que también podría llamar, con Arendt, la «brecha entre el pasado y el futuro», que no es despertar el sueño de la maestría, sino la experiencia de poder comenzar: el «comienzo de ser», como escribió Nancy. Un ser que al que podemos imaginar (comenzando a) ejercitar, considerar, pensar, y tal vez también soñar. Se necesita que su relación hacia el mundo y a sí

19 Por supuesto, hay pinturas murales muy antiguas que se encuentran fuera de las cuevas (por ejemplo, las famosas pinturas de Bradshaw. http://www.bradshawfoundation.com/index.php, pero como dice Nancy: «la pintura que comienza en las grutas (pero también las grutas que la pintura inventa)...».

20 A menudo se han hecho comparaciones entre las cuevas y el cine, pero sorprendentemente poco entre las cuevas y las aulas, o si es así, estas estaban en su mayoría en línea con la fábula de Platón de la cueva como prisión. La lectura de Michel Serres (2015, pp. 202-209) es una notable excepción. 
mismo esté en sus propias manos sin que esto se convierta en un dominio, una captura, captación o un acto de explotación, sino más bien uno de apreciación.

Experimentar el compartir un mundo con el que se puede relacionar y del que puede hablar, o por el que se siente invitado o incluso instado, provocado a hablar. Experimentar un comienzo compartido con el mundo y la posibilidad de ser parte de un público de espectadores y monstradores que comparte el lugar, comparte los ejercicios de trazado, comparte las paredes y lo que aparece en ellas, comparte la exposición y tiene la posibilidad de comunicarse. Las paredes ofrecen un espacio y crean un milieu como un agujero en el tiempo y el entorno habitual.

La fábula educativa de la caverna — y es una fábula, como lo fue la de Platón según su propio palabras, una «fantasía», para usar la frase de Mondzain, para poblar nuestra imaginación— no es la biografía de un ser que se convierte en filósofo en el sentido de Platón, pero tal vez la de un ser que se convierte en artista, en el sentido muy general en que Rancière entiende que todo el mundo es un artesano, es decir, un manipulador21 («un manieur») (Rancière, 1987, p. 110) y que el Diccionario de Oxford indica como «un seguidor de una persecución en la que la habilidad viene por el estudio o la práctica». Esta historia no requiere de un filósofo que guíe la salida de la caverna hacia la luz de un mundo trascendente y que nos cuente que no sabemos lo que estamos viendo y diciendo. Pero la historia sí sugiere que podemos encontrar alguna ayuda del pedagogo, quien va a lo largo del camino a la caverna y ofrece apoyo en este esfuerzo (de la voluntad) que exige un cierto grado de coraje, ya que la caverna no la casa y siempre es un poco incómoda. Recuerde que pedagogo era el nombre en griego antiguo para los esclavos que llevaban a los niños a la escuela, sacándolos de la casa, el oikos, y de la sociedad, la polis. Y podemos imaginar al maestro no solo como el que proyecta imágenes en la pared, sino también como quien introduce o incita palabras, nombrando el mundo de tal manera que se hace un mundo disponible para un ser que también se pone a disposición de sí mismo — disponible, es decir, para la contemplación, el estudio y ejercicio, para la (auto)educación-. Un maestro que, como afirma Rancière sobre el maestro emancipador, se queda en la puerta para asegurarse de que uno no evita el esfuerzo y la disciplina necesarios para estar atento al mundo, para estudiar y ejercitar las manos y los ojos (Rancière, 1987). La fábula educativa también trata de la apertura y la renovación del mundo. Esto no se concibe ni como un retorno ni como una conversión, sino como un recomenzar que continúa nuestro errar sin destino. Como escribe Michel Serres: retomando «el engendrar y dar a luz a un niño nuevamente» (Serres, 1997, p. 49, la cursiva es mía). Perteneciendo, partiendo y deviniendo. 
La educación no es principalmente ocuparse de la verdad y la opinión; no se trata tanto sobre la ignorancia y la ilusión. La educación trata sobre la cuestión de la compañía, de estar en compañía de otros y con las cosas (es decir, abriendo y revelando el mundo), sobre habilitar y exponer. La fábula ofrece un escenario diferente de la (auto)educación del ser humano, afirmando una creencia en la ausencia de cualquier orden preexistente y cualquier naturaleza o destino humano. No se trata de ilustración por el sol, sino sobre la pequeña luz que permite que algo comience y que nos permite atender a algo en la oscuridad (de la caverna) que nos ayuda a navegar, a hacer y de la (auto)educación del ser humano, afirmando una creencia en la ausencia de cualquier orden preexistente y cualquier naturaleza o destino humano. No se trata de la iluminación. por el sol, sino sobre la pequeña luz que habilita que algo comience y que nos permite atender a algo en la oscuridad (de la caverna) que nos ayuda a navegar, a hacer y encontrar un camino. Según Serres, ya no es la luz brillante del sol, sino las pequeñas luces de una noche estrellada las que ofrecen una buena imagen de lo que nuestro «saber» y nuestra existencia se tratan. La luz brillante es más bien una metáfora de la ideología (2014, p. 319).

En consonancia con la fábula de la caverna de Platón, parece existir un enfoque filosófico de la educación que, de hecho, parte de la experiencia de los adultos que expresan «una decepción con el mundo» (Cavell, 2005, p. 3) y de llevar «una vida que exige una transformación o reorientación» (Cavell, 2005, p. 11). La filosofía, allí, se concibe, como escribe Cavell, como la conducción del «alma, prisionera y distorsionada por la confusión y la oscuridad, hacia la libertad del día» (Cavell, 2005, p. 4). El propio Cavell lo ve claramente cuando llama a la filosofía en este sentido una «educación de adultos» (Cavell, 1999). La historia de la caverna educativa, sin embargo, que toma la caverna no (o no solo) como una metáfora sino como un lugar real, ofrece un enfoque pedagógico de la educación que no parte de la experiencia (adulta) de decepción, confusión o distorsión, sino que de la experiencia (infantil) de ser capaz de poder comenzar, de ser curioso y atraídos a entrar en la caverna por la alegría — siendo la alegría la firma del evento por excelencia-22 del ejercicio-producción-descubrimiento de un nuevo grado de libertad y (del vínculo a) un nuevo mundo. Tal vez esto está relacionado con la filosofía en el sentido de ejercicio - epimeleia - y, seguro, Cavell también recurre a esta experiencia. Pero lo importante es que, como punto de partida, un ejercicio como este tiene que ver con el descubrimiento, la revelación, la compañía y el cuidado del mundo y no tanto sobre el cuidado de sí mismo o el arte de vivir.23 Y la educación no consiste, al principio, en decir a los demás que están

22 Cf.: «La joie, pourrait-on dire, est la signature de l'événement par excellence [...] Joie du premier pas, même inquiet» (Stengers, 2013, p. 142).

23 Como afirma Arendt, «la escuela no se trata sobre el arte de vivir» (2006, p. 192). 
equivocados, «diciéndoles que no saben lo que dicen»(Cavell, 1999, p. 326), sino en de presentar el «mundo», fuera y al lado de ellos mismos, diciéndoles que deberían atender e intentar. Eso parece ser lo que está en juego para los animales que van a la escuela.

\section{Referencias bibliográficas}

Arendt, H. (2005). Socrates. En: J. Kohn (Ed.), The promise of politics (pp. 5-39). Nueva York: Schocken Books. (2006). The crisis in education (1958). In Between past and future (pp. 170-193). New York: Penguin.

Azéma, M. (2011). La Préhistoire du cinéma. Origines paléolithiques de la narration graphique et du cinématographe. París: Editions Errance.

Bachelard, G. (1948). La Terre et les Rêveries du repos. París: José Corti.

Barberà, P. G. (2010). The "Image" of the Cave and the Constant Temptation to Correct Plato: Benjamin Jowett as an Example. Estudios Clásicos. Traducir a los Clásicos, 1, 105-115. Recuperado de https://pdfs.semanticscholar.org/e7dd/a3361900a14d35403f8359b1e9403cd706a5.pdf.

Bartlett, A. J. (2011). Badiou and Plato. An Education. Edinburgo: Edinburgh University Press.

Bataille, G. (1988). Le passage de l'animal à l'homme et la naissance de l'art. (1953). En: OEuvres Complètes XII (pp. 259-277). París: Gallimard.

Berger, J. (2002, octubre 12). Past Present. The Guardian. Recuperado de http://www.theguardian.com/artanddesign/2002/oct/12/art.artsfeatures3.

Biesta, G. (2013). Beyond learning: Democratic education for a human future. Boulder: Paradigm Press.

Blacker, D. (2013). The falling rate of learning and the neoliberal endgame. Winchester: Zero-Books.

Blumenberg, H. (1993). Light as a metaphor for truth at the preliminary stage of philosophical concept formation. En: D. M. LEVIN (Ed.). Modernity and the hegemony of vision (pp. 36-44). Berkeley: University of California Press.

Burch, K. (2011). An Enlightenment 'Experience' and Plato's Parable of the Cave: Reflections on a Vision-quest Gone Awry. Philosophical Studies in Education, 42, 6-16. Recuperado de https://eric.ed.gov/?id=EJ960322.

Cavell, S. (1999). The claim of reason. Oxford: Oxford University Press.

(2005). Cities of words: Pedagogical letters on a register of the moral life. Cambridge, MA: Harvard University Press.

Clottes, J. (2008). L’art des cavernes préhistoriques. París: Phaidon.

Flüsser, V. (2011). Into the Universe of Technical Images. Minneapolis: University of Minnesota Press.

Foucault, M. (1984). Nietzsche, Genealogy, History. En P. RABINOW (Ed.), The Foucault Reader (pp. 76-100). Nueva York: Pantheon.

(1986). Of Other Spaces (1967). Diacritics, 16 (1), 22-27. 
Heidegger, M. (2001). Sein und Wahrheit. Freiburger Vorlesungen Sommersemester 1933 und Wintersemester 1933/34. (Ed. H. Tietjen. Gesamtausgabe Bd 36/37) FFM: Klostermann.

Horkheimer, M. (2002). Traditional and Critical Theory. (1937). En: M. HoRKHEIMER. Selected Essays. (Matthew J. O’Connell and others, Trans.) (pp. 188-243). Nueva York: Continuum.

Ingold, T. (2015). The Life of Lines. Londres: Routledge.

Jaeger, W. (1973/1933). Paideia. Die Formung des Griechischen Menschen. Berlín/Nueva York: Walter DE GRUYTER. Jouary, J. P. (2001). L'art paléolithique. Réflexions philosophiques. París: L’Harmattan.

(2012). Préhistoire de la beauté. Et l'art créa l'homme. Bruselas: Les impressions nouvelles.

Kohan, W. (2014). Childhood, Education and Philosophy. Londres-Nueva York: Routledge.

Larrosa, J. (2011). Endgame: Reading, Writing, Talking (and perhaps thinking) in a Faculty of Education. En: M. SIMONS y J. MASSCHELEIN (Eds.). Rancière, public education and the taming of democracy (pp. 166-186). Chichester: Wiley-Blackwell.

Latour, B. (1986). Visualisation and cognition: Thinking with eyes and hands. En: H. KuKLICK (Ed.), Knowledge and Society Studies in the Sociology of Culture Past and Present (vol. 6, pp. 1-40). Greenwich: Jai Press.

(2016). Introduction: Let’s Touch Base! En: B. Latour y C. Lecrecq (Eds.), Reset Modernity (pp. 11-23). Cambridge, MA/Londres: MIT Press.

Leroi-Gourhan, A. (1965). La Préhistoire de L’Art occidental. París: Éditions Mazenod.

Lewis, T. (2012). Rousseau and the Fable: Rethinking the Fabulous Nature of Educational Philosophy. Educational Theory, 62 (3), 323-341. doi: 10.1111/j.1741-5446.2012.00449.x. (2013). On Study: Giorgio Agamben and Educational Potentiality. Nueva York: Routledge.

Masschelein, J. y Simons, M. (2013). In Defense of the School. A Public Issue. Leuven: ECs Publishers.

Miller, R.; Shapiro, H. y Hilding-Hamann, K. (2008). School's over: Learning spaces in Europe in 2020: An imagining exercise on the future of learning. Sevilla: European Commission Brussels: Joint Research Center. Recuperado de http://ipts.jrc.ec.europa.eu/publications/pub.cfm?id=1780

Mondzain, M.-J. (2007). Homo spectator. París: Bayard.

Nancy, J. L. (1996). The Muses. Stanford: Stanford University Press.

(2016). The Present (of) time. (Lecture given at the Institute of Philosophy, Leuven, March 2016).

Rancière, J. (1987). Le maitre ignorant. Cinq Leçons sur l'émancipation intellectuelle. París: Fayard. 
(2000). Dissenting Words. A conversation with Jacques Rancière. Diacritics, 30 (2), 113-126. Recuperado de https://www.jstor.org/stable/1566474?seq=1.

Serres, M. (1997). The Troubadour of Knowledge. (S. Glaser \& W. Paulson, Trans.). Ann Arbor: The University of Michigan Press.

(2014). Pantopie: de hermès à petite poucette. (Entretiens avec Martin Legros \& Sven Ortoli). París: Le Pommier.

(2015). Le gaucher boiteux: puissance de la pensée. París: Le Pommier.

Simons, M. y Masschelein, J. (2008). The Governmentalization of Learning and the Assemblage of a Learning Apparatus. Educational Theory, 58 (1), 391-415. doi: 10.1111/j.1741-5446.2008.00296.x

Stengers, I. (2013). Au temps des catastrophes. Résister à la barbarie qui vient. París: La Découverte.

Verhoeven, C. (1983). Mensen in een grot. Beschouwingen over een allegorie van Plato. Baarn: Ambo 